\title{
Effect of Riboflavin, Choline, Pantothenic Acid and Vitamin A on the Excretion of Sodium in Urine of Rats
}

\author{
By \\ Tatsuo Koyanagi and Shinichi Hareyama* \\ Laboratory of Nutrition, Faculty of Agriculture, Tohoku University, \\ Sendai and *Department of Agriculture, Iwate University, \\ Morioka
}

(Received for publication, July 11, 1962)

In previous publications ${ }^{1,2,3)}$ authors reported the preventive effect of riboflavin, choline, pantothenic acid and vitamin A on the occurrence of blood hypertension induced by the high salt diet. The present report concerns the results of the investigation of excretion of sodium in urine, sodium content of various tissues together with the pantothenic acid content in liver of rats fed high salt diet with or without vitamin supplement.

\section{EXPERIMENTAL}

Male rats of the Wister strain, weighing $40-60 \mathrm{~g}$, were housed separately in metal cages and were given a diet having the following composition: milled washed rice, 77 ; casein, 5 ; soybean meal (solvent), 15 ; calcium carbonate, 0.5 ; sodium chloride, 1.0; dried carrot powder, $0.2(\mathrm{~g})$ and thiamine- $\mathrm{HCl}, 0.1(\mathrm{mg})$. The food was made into paste by adding hot water, and cooked. This diet contained an adequate amount of protein but did not allow the accumulation of riboflavin, pantothenic acid, choline and vitamin $A$ in rats.

After the prefeeding period of 2 months they were divided into five groups of six animals each and fed the experimental diets having low protein and high salt with or without supplement of vitamin, as shown in Table I. The amount of diet was restricted to $13 \mathrm{~g}$ per rat per day, and water was given ad libitum.

In order to determine the excretion of sodium, urine was collected during 24 hrs in the metabolism cage and sodium was determined flamephotometrically using Beckman spectrophotometer. For the determination of that of tissues the animals were decapitated and about one $g$ of liver, muscle, one kidney and one femur were weighed in porcelain dishes and sodium content of them was determined after they were made into ash. 
Table I. Experimental Groups and Their Diet Composition

\begin{tabular}{l|c|c|c|c}
\hline \multicolumn{1}{c|}{ Group } & $\begin{array}{c}\text { Riboflavin } \\
\mathrm{mg}\end{array}$ & $\begin{array}{c}\text { Choline chloride } \\
\mathrm{mg}\end{array}$ & $\begin{array}{c}\text { Ca pantothenate Vitamin A** } \\
\mathrm{mg}\end{array}$ & \\
\hline $\begin{array}{l}\text { Basal* } \\
\text { Riboflavin } \\
\text { Choline }\end{array}$ & 1 & 100 & 2 & 160 \\
$\begin{array}{l}\text { Pantothenic acid } \\
\text { Vitamin A }\end{array}$ & & & & \\
\hline
\end{tabular}

* Milled washed and dried rice, 91; defatted soybean meal, 5; sodium chloride, 2.5; calcium carbonate, 0.5 ; carrot powder, 1 ; soybean oil, 1 (g); thiamine-HCl, 0.1 (mg).

** Shark liver oil concentrate

Pantothenic acid in liver was determined microbiologically by the method of Nishi et al.4) using Lactobacillus arabinosus. One to $2 \mathrm{~g}$ of liver were homogenized with 9 parts of distilled water, heated in a boiling water bath for three minutes and rehomogenized. Aliquots were used in a incubation mixture to release the pantothenic acid from the tissue.

At the end of the feeding experiment the systolic blood pressure was determined by the method of Williams et al. ${ }^{5}$ )

\section{RESULTS AND DISCUSSION}

During the course of experiment analysis of sodium in the $24 \mathrm{hr}$ urine was conducted three times namely during the 43-55th, 56-67th and 75-89th days of the experimental diet. Since the results of three measurements were much the same in their tendency, data only on the $75-89$ th days are presented in Table II. In the riboflavin, choline or pantothenic acid supplemented groups the sodium excretion increased along with the amount of urine. The effect of vitamin A on the promotion of excretion of sodium was less remarkable.

The results of the determination of blood pressure during the 75-89th days of the experimental diet show the higher value in the basal group and the lower

TABle II. Effect of Dietary Riboflavin, Choline, Pantothenic Acid and Vitamin A on the Urine Volume, Sodium Excretion and Blood Pressure of Rats

\begin{tabular}{|c|c|c|c|c|c|}
\hline Group & $\begin{array}{c}\text { Body weight } \\
\text { initial } \\
\mathrm{g}\end{array}$ & $\begin{array}{c}\text { Av. weight gain } \\
\text { in } 3 \text { months } \\
\mathrm{g}\end{array}$ & $\begin{array}{c}\text { Urine } \\
\text { per day } \\
\text { ml }\end{array}$ & $\begin{array}{c}\text { Sodium excre- } \\
\text { tion per day } \\
\text { mg }\end{array}$ & $\begin{array}{l}\text { Blood } \\
\text { pressure } \\
\text { mm Hg }\end{array}$ \\
\hline Basal & $163.7(6)^{*}$ & $21.9 \pm 38.9^{k *}$ & $4.78 \pm 0.98$ & $48.1 \pm 2.8$ & $136 \pm 4$ \\
\hline Riboflavin & $162.6(6)$ & $54.5 \pm 18.4$ & $6.13 \pm 0.83$ & $61.8 \pm 10.7$ & $124 \pm 2$ \\
\hline Choline & $160.3(6)$ & $19.0 \pm 21.9$ & $6.13 \pm 1.54$ & $60.1 \pm 13.0$ & $123 \pm 3$ \\
\hline Pantothenic acid & $167.3(6)$ & $21.5 \pm 23.6$ & $6.03 \pm 1.25$ & $60.0 \pm 10.1$ & $121 \pm 6$ \\
\hline Vitamin A & $163.9(6)$ & $-6.8 \pm 25.6$ & $5.65 \pm 2.91$ & $49.2 \pm 26.2$ & $124 \pm 3$ \\
\hline
\end{tabular}

* Figures in parentheses indicate number of rats.

** Mean value \pm standard deviation 
ones in the vitamin supplemented groups (Table II). This is in accordance with our preceding reports. ${ }^{1,2,3)}$

The effect of the vitamins on the sodium content of liver, muscle, kidney and bone is shown in Table III. Grossly, the results obtained are similar when either type of diet is fed. Still in the case of muscle which is the tissue containing above 40 per cent of body water of rats, the highest sodium concentration was found in basal group and this may have almost negligible effect on the elevation of blood pressure.

The results of pantothenic acid determination of liver of rats fed high salt diet with supplement of various vitamins are shown in Table III. The basal group had strikingly low pantothenic acid content as compared with the supplemented groups. The low pantothenic acid value in liver of rats of the basal group may account for the decrease of preventive ability against elevation of blood pressure in this group, because the vitamin has a profound effect on the formation of adrenal hormon needed for the excretion of sodium.

Thus one of the preventive effects of supplemented vitamin against the occurrence of hypertension seems to be caused by facilitation of the excretion of sodium in the urine.

TABLE III. Effect of Dietary Riboflavin, Choline, Pantothenic Acid and Vitamin A on the Sodium Content of Various Tissues and Pantothenic Acid Content in Liver of Rats*

\begin{tabular}{|c|c|c|c|c|c|}
\hline \multirow[t]{2}{*}{ Group } & \multicolumn{4}{|c|}{$\begin{array}{l}\text { Sodium } \\
\mathrm{g} / 100 \mathrm{~g}\end{array}$} & \multirow{2}{*}{$\begin{array}{c}\begin{array}{c}\text { Pantothenic acid } \\
\mathrm{mg} / 100 \mathrm{~g}\end{array} \\
\text { Liver, dried }\end{array}$} \\
\hline & Muscle*** $_{* * *}^{*}$ & Liver & Kidney & Bone & \\
\hline Basal & $0.16 \pm 0.01$ & $0.19 \pm 0.01$ & $0.42 \pm 0.03$ & $0.37 \pm 0.03$ & $6.9 \pm 2.2$ \\
\hline Riboflavin & $0.15 \pm 0.01$ & $0.20 \pm 0.01$ & $0.45 \pm 0.03$ & $0.37 \pm 0.02$ & $15.8 \pm 3.1$ \\
\hline Choline & $0.13 \pm 0.00$ & $0.19 \pm 0.01$ & $0.45 \pm 0.05$ & $0.34 \pm 0.04$ & $17.0 \pm 2.2$ \\
\hline Pantothenic acid & $0.14 \pm 0.02$ & $0.19 \pm 0.01$ & $0.42 \pm 0.05$ & $0.34 \pm 0.06$ & $16.3 \pm 2.5$ \\
\hline Vitamin A & $0.14 \pm 0.02$ & $0.18 \pm 0.02$ & $0.49 \pm 0.06$ & $0.37 \pm 0.01$ & $18.9 \pm 5.0$ \\
\hline \multicolumn{6}{|c|}{ * Average value of 6 rats of each group } \\
\hline \multicolumn{6}{|c|}{ ** M. biceps femoris } \\
\hline \multicolumn{6}{|c|}{$* * * \quad$ Mean \pm standard deviation } \\
\hline
\end{tabular}

\section{SUMMARY}

1. Sodium excretion of rats was increased by the supplement of riboflavin, choline, pantothenic acid or vitamin $\mathrm{A}$ to the diet.

2. Pantothenic acid concentration in the liver of rats was higher in the vitamin supplemented group than in the liver of those unsupplemented.

3. Authors have assumed that one of the preventive effects of the vitamins against the elevation of blood pressure would be the facilitating action of these vitamins on the excretion of sodium. 


\section{References}

1) Koyanagi, T. \& Hareyama, S., Report of Agricultural College of Iwate Univ., 1955, $2,177$.

2) Koyanagi, T. \& Hareyama, S., J. Vitaminology, 1957, 3, 303.

3) Koyanagi, T. \& Hareyama, S. \& Ota, M., Bull. Agr. Chem. Soc. of Japan, 1959, $23,3$.

4) Nishi, H., King, T.E. \& Cheldelin, V.H., J. Nutrition, 1950, 41, 279.

5) Williams, J.R., Harrison, J.R. \& Grollman, A., J. Clin. Invest., 1939, 18, 373. 